\title{
An electrochemical codeine sensor based on CdS nanparticle label
}

\author{
Wei Xiong ${ }^{1}$, SuFang $\mathrm{Wu}^{2}$,Fusheng Liao ${ }^{1}$, Nian Hong ${ }^{1}$, Hao Fan ${ }^{1 *}$ \\ ${ }^{1}$ Department of Pharmacy, JiangXi University of Traditional Chinese Medicine, JiangXi 330004, \\ China \\ ${ }^{2}$ JiangXi Nursing Vocational and Technical College,JiangXi 330004, China

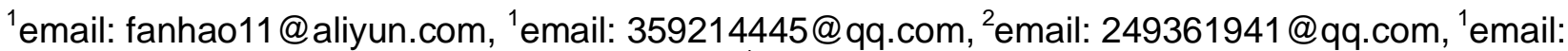 \\ 327295625@qq.com 1email: 470580951@qq.com
}

\begin{abstract}
Keywords: Electrochemical sensor, codeine, CdS nanoparticles, aptamer
Abstract. In the present study, we describe an electrochemical sensor for codeine detection by using the DNA aptamers against codeine. In the sensing protocol, a dually-labeled DNA Aptamer probe was designed to be labeled at one end with HS, and at its another end with an dabcyl as an electrochemical tag to produce electrochemical signal from recongization occurrence. One special electrochemical marker was prepared by modifying CdS nanoparticle with -cyclodextrins (ab. CdS-CDs), which employed as electrochemical signal provider and would conjunct with the thrombin probe modified electrode through the host-guest recognition of CDs to dabcyl. With codeine adding, aptamer folding allows the CdS-CDs into soultion which caused a increased current signal. This sensor have the ability to detect $27 \mathrm{pM}$ codeine.
\end{abstract}

\section{Introduction}

Codeine(3-methylmorphine) is an opiate that is widely used to treat mild to moderate pain and cough suppression. It is the secondmost predominant alkaloid in opium with a mild sedative effect [1]. Despite its extensive medical applications, codeine is often abused for its euphoric and depressant effects as well as to prevent opiatewithdrawal [2]. It is very harmful to take codeine in large quantities and now it has been attributed to be controlled medicine in mostcountries. It is very meaningful to detect codeine in forensic analysis or clinic diagnostics. There are many methods, such as UV spectrophotometric techniques [3], gas chromatography-mass spectrometry[4], capillary electrophoresis[5] and high-performanceliquid chromatography [6], have been applied in the determination ofcodeine. Although these above assay methods have accuracy and sensitive detection limit, it also has the obvious disadvantages of valuable apparatus, complicated manipulation and unapproachable in applying in field-tests. Therefore, it is highly desired to set up a sensitive method for detection of codeine.

In this article, the nolve electrochemical sensor was constructed for codeine detction. As illustrated in Fig. 1, two key components were employed for our electrochemical sensing codeine strategy. One component is the CdS nanoparticle surface-modified -cyclodextrins (CdS-CDs), which was used as both electrochemical signal provider and the host recognizer during the host-guest molecular recognition. The other one component is the 15-base codeine aptamer, which was terminal-labeled with dabcyl at its 5 end as -CD's typical guest and labeled thiol at its 3 end for pre-immobilization onto Au electrode via the $\mathrm{Au} \mathrm{S}$ bond. The aptasensor was completely fabricated after CdS-CDs were interacted with aptamer-modified electrode through the host-guest recognition between dabcyl labeled at aptamer and -cyclodextrins-modified on CdS. During codeine detection, conformational change of the aptamer happened and forced CdS-CDs away from the electrode surface, thus the capture of target onto electrode was translated via the electrochemical current signal offered by released CdS-CDs. Compare to previous methods, CdS-CDs play the role of target recognition and the signal provider which make this present method display an simple-step detection and sensitivity. Therefore, this electrochemical aptasensor is expected to have wide applications in codeine monitoring. 


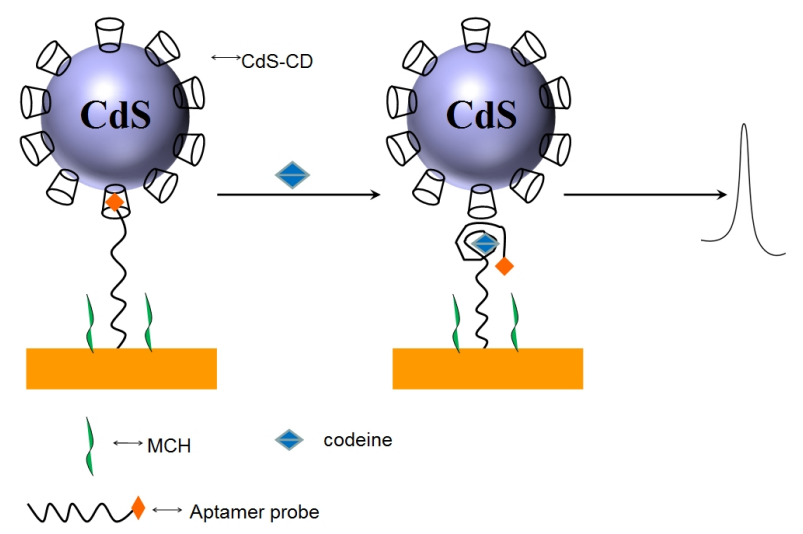

Fig.1 Schematic representation of the procedure to prepare electrochemical sensor for the determine of codeine.

\section{Experiment section}

Apparatus Differential pulse voltammetry (DPV) measurements were performed using a CHI 660 Electrochemical Analyzer (CHI Instrument Inc., USA). The JB-1 stirring machine (Branson, Shanghai, China) and a TDL-16B centrifuge (Anting Science Instrument Inc., Shanghai, China) were used. The three-electrode electrochemical detection system consisted of a Au working electrode with sensing area of $3.14 \mathrm{~mm} 2, \mathrm{a} \mathrm{Ag} / \mathrm{AgCl}$ reference electrode (saturated $\mathrm{KCl}$ ) and a platinum wire counter electrode. The detection was carried out in a $5 \mathrm{ml}$ electrochemical cell containing a mercury-coated glassy carbon working electrode ( $2 \mathrm{~mm}$ diameter), an $\mathrm{Ag} / \mathrm{AgCl}$ reference electrode, and a platinum wire counter electrode.

Preparation of nano $\mathbf{C d S ~} \mathrm{Cd}\left(\mathrm{NO}_{3}\right)_{2}$ and $\mathrm{Na}_{2} \mathrm{~S}$ solutions were filtered through a $22 \mathrm{~m}$ microporous membrane filter prior to use. CdS nanoparticles were prepared according to the literature [7] by using mercaptoacetic acid as the stabilizer. In brief, 9.221 mercaptoacetic acid was added to $50 \mathrm{ml} 0.4 \mathrm{mM}$ $\mathrm{Cd}\left(\mathrm{NO}_{3}\right)_{2}$ solution, and then the $\mathrm{pH}$ was adjusted to 7 with $0.5 \mathrm{M} \mathrm{NaOH}$. The solution was bubbled with nitrogen for $30 \mathrm{~min}$, followed by the slow addition of $1.34 \mathrm{mM} \mathrm{Na}_{2} \mathrm{~S}$ to the mixture solution. The molar ratio of $\mathrm{Na}_{2} \mathrm{~S}$ to $\mathrm{Cd}\left(\mathrm{NO}_{3}\right)_{2}$ was kept at 2.5. The reaction was carried out for $24 \mathrm{~h}$ under nitro-gen protection and then gradually a brown colloid which is the CdSnanoparticles covered with a carboxyl group was obtained. As TEM images show, the diameter of CdSnanopatricles was about $7 \mathrm{~nm}$.

Preparation of Per-6-thio- $\beta$-cyclodextrin Per-6-thio- $\beta$-cyclodextrin (SH- $\beta-C D)$ is synthesized according to the literature, but step slightly improved. The resulting precipitate was carefully filtered off and dried under vacuum to yield Per-6-thio- $\beta$-cyclodextrin $(0.85 \mathrm{~g}, 83 \%)$ as an off-white powder. mp 134-136 ${ }^{\circ} \mathrm{C} .{ }^{1} \mathrm{H}$ NMR $(400 \mathrm{MHz}$, DMSO-d6) $\delta 5.92(\mathrm{~d}, J=6.0 \mathrm{~Hz}, 7 \mathrm{H}), 5.82(\mathrm{~s}, 7 \mathrm{H}), 4.93(\mathrm{~s}, 7 \mathrm{H})$, $3.68(\mathrm{t}, J=6 \mathrm{~Hz}, 7 \mathrm{H}), 3.61(\mathrm{t}, J=7.5 \mathrm{~Hz}, 7 \mathrm{H}), 3.19(\mathrm{br} \mathrm{d}, J=15 \mathrm{~Hz}, 7 \mathrm{H}), 2.77-2.74(\mathrm{~m}, 7 \mathrm{H}), 2.13(\mathrm{t}$, $J=6.0 \mathrm{~Hz}, 7 \mathrm{H}$ ). MS (ESI) m/z [M + Na]+: 1269.1920 (see fig.2). 


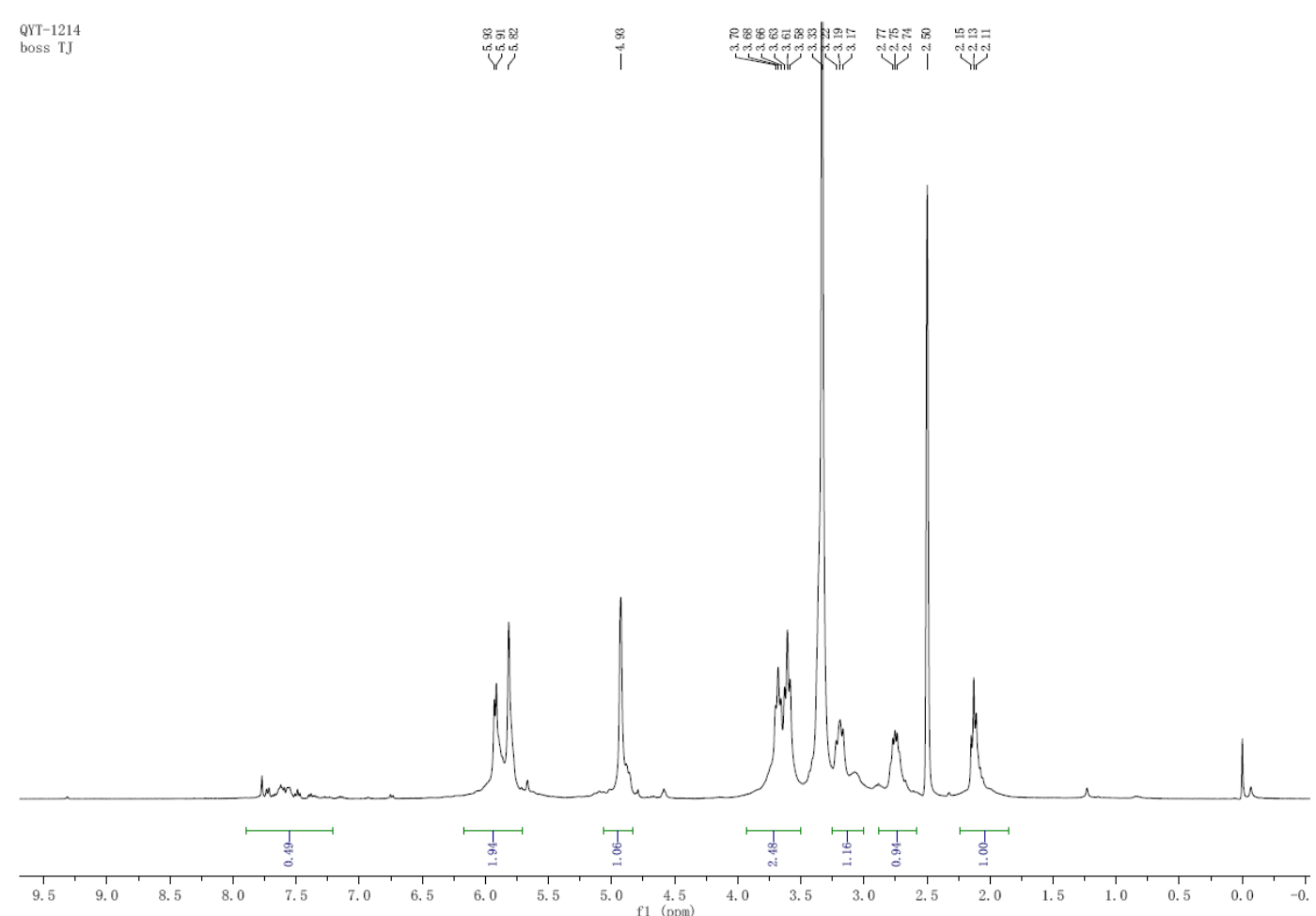

Fig. $2{ }^{1}$ H NMR of Per-6-thio- $\beta$-cyclodextrin

\section{Results and discussion}

\section{Principle of detection of codeine}

The assay procedure was initiated by incubating the aptasensor with codeine in phosphate buffer solution at $37{ }^{\circ} \mathrm{C}$ for $40 \mathrm{~min}$. During which, the aptamer would prefer to bind with codeine due to the strong combination between aptamer-to-protein and then the CdS-CDs which previously combined with aptamer were released away from the electrode surface (Fig. 1 ) into the buffer solution. These CdS-CDs were dissolved by adding $20 \mathrm{~L}$ of $1.0 \mathrm{M} \mathrm{HNO}_{3}$ into the buffer solution, and then $1.8 \mathrm{~mL}$ acetate buffer $(0.1 \mathrm{M}, \mathrm{pH} 5.3)$ was added into it. Electrochemical detection of the dissolved $\mathrm{Cd}^{2+}$ was performed in the above acetate buffer solution by applying $-1.0 \mathrm{~V}$ for $5 \mathrm{~min}$ at one mercury-film electrode to reduce $\mathrm{Cd} 2+$ into $\mathrm{Cd}$ film. After which, DPV was immediately performed from -0.90 to $-0.54 \mathrm{~V}$ (Incr E $0.004 \mathrm{~V}$, amplitude $0.05 \mathrm{~V}$, pulse width $0.05 \mathrm{~s}$, pulse period $0.2 \mathrm{~s}$ ), resulting in an electrochemical signal due to the oxidation of Cd film. The DPV peak height at the potential of -0.7 $\mathrm{V}$ was used in all measurements, which was related to the released amount of the CdS nanoparticles from the electrode surface.

\section{Codeine determination}

In the experiments, the aptasensor was incubated with the different concentration of codeine, the DPV signal owing to the released CdS-CDs was increased with the codeine concentration, which was logarithmically related to the target protein concentration from $53 \times 10^{-12}$ to $53 \times 10^{-9} \mathrm{M}$. The equation for the resulting calibration plot was calculated as $\mathrm{y}=0.32 \log \mathrm{x}-0.072$ ( $\mathrm{x}$ is the concentration of target codeine divided by $\mathrm{pM}$, y is the DPV peak current value) with correlation coefficient of 0.9832 and detection limit of $27 \times 10^{-12} \mathrm{M}$.

\section{Conclusions}

The present study has introduced a novel electrochemical aptamer biosensor based on CdS-CDs as signal label had been proposed to determine codeine and a very low detection limit of 27 pM was achieved. Therefore, this electrochemical sensor is expected to have wide applications in medine monitoring. 


\section{Acknowledgements}

This work was financially supported by the NSF of China (Grant No. 21265007) and JiangXi Science and Technology Committee (Grant No. 20122BAB215024, 20132BAB215032 ).

\section{References}

[1] M.A. Zayed, M.F. El-shahat, S.M. Abdullah, Spectrochim. Acta A 61 (2005),1955.

[2] D.G. Williams, A. Patel, R.F. Howard, Br. J. Anaesth. 89 (2002), 839.

[3] T.T. Duong, D.H. Vu, Asian J. Res. Chem. 2 (2009), 143.

[4] L.A. Broussard, L.C. Presley, T. Pittman, R. Clouette, G.H. Wimbish, Clin. Chem. 43 (1997), 1029.

[5] A. Alnajjar, J.A. Butcher, B. McCord, Electrophoresis 25 (2004), 1592.

[6] Z.R. Chen, F. Bochner, A. Somogyi, J. Chromatogr. 491 (1989), 367.

[7] A.E. Radi, L.A. Sanchez, E. Baldrich and C.K. O'Sullivan, Anal. Chem. Vol.77 (2005), p.6320 